
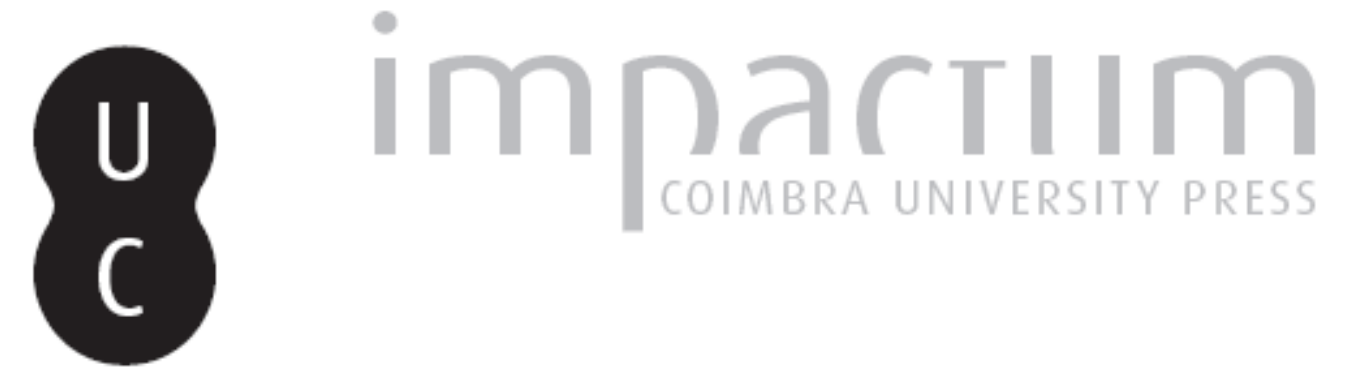

\title{
O sonho da perenidade na Arquitectura cultual do Antigo Egipto: para a glória de Amon
}

\author{
Autor(es): $\quad$ Ferreira, J. M. Simões
}

Publicado por: Centro de História da Universidade de Lisboa

URL persistente:

URI:http://hdl.handle.net/10316.2/23887

DOI:

DOI:http://dx.doi.org/10.14195/0871-9527_18_15

Accessed : $\quad$ 26-Apr-2023 15:50:43

A navegação consulta e descarregamento dos títulos inseridos nas Bibliotecas Digitais UC Digitalis, UC Pombalina e UC Impactum, pressupõem a aceitação plena e sem reservas dos Termos e Condições de Uso destas Bibliotecas Digitais, disponíveis em https://digitalis.uc.pt/pt-pt/termos.

Conforme exposto nos referidos Termos e Condições de Uso, o descarregamento de títulos de acesso restrito requer uma licença válida de autorização devendo o utilizador aceder ao(s) documento(s) a partir de um endereço de IP da instituição detentora da supramencionada licença.

Ao utilizador é apenas permitido o descarregamento para uso pessoal, pelo que o emprego do(s) título(s) descarregado(s) para outro fim, designadamente comercial, carece de autorização do respetivo autor ou editor da obra.

Na medida em que todas as obras da UC Digitalis se encontram protegidas pelo Código do Direito de Autor e Direitos Conexos e demais legislação aplicável, toda a cópia, parcial ou total, deste documento, nos casos em que é legalmente admitida, deverá conter ou fazer-se acompanhar por este aviso.

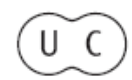



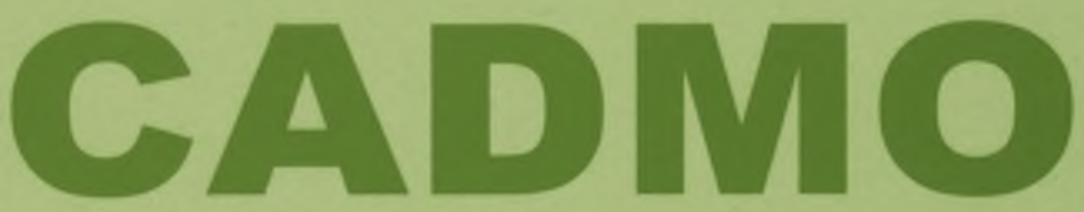

Revista de História Antiga

\author{
Centro de História \\ da Universidade de Lisboa
}

18

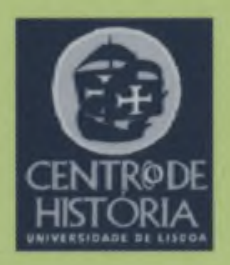

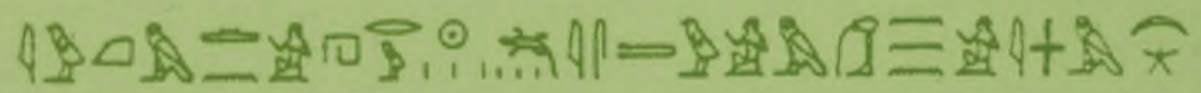

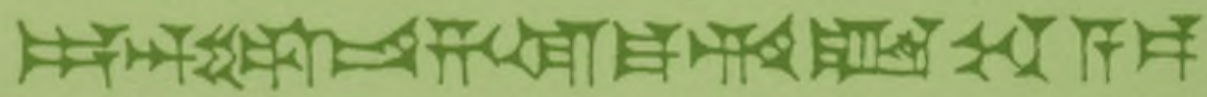

MHNIN AEI $\Delta$ E $\Theta E A ~ \Pi H \Lambda H I A \triangle E \Omega$ 


\section{O SONHO DA PERENIDADE NA ARQUITECTURA CULTUAL DO ANTIGO EGIPTO: PARA A GLÓRIA DE AMON

\author{
AMEN-HOTEP III, GRANDE CONSTRUTOR DE PALÁCIOS DIVINOS
}

"O coração de sua majestade compraz-se a construir monumentos muito grandes; uma coisa semelhante nunca tinha acontecido desde os primeiros tempos do Duplo País.

Ele fez um monumento para seu pai Amon, senhor dos tronos do Duplo País, construindo para ele um templo augusto a oeste de Tebas, cujo muro de encerramento, em bela pedra branca de grés, convinha (appartenait) à eternidade e à infinita duração."(1)

É desta maneira que começa a enumeração e descrição das grandes construções empreendidas por Amen-hotep III, que terá reinado entre 1408-1372 a. C. (2), logo, em pleno Império Novo, quando a construção e a arquitectura cultual, desvinculadas já de uma exclusiva ou essencial função funerária, se avultaram mais, dando origem a numerosos templos, e outros monumentos destinados ao culto funerário e religioso ${ }^{(3)}$. O texto que vai servir como referência consta da antologia Textes sacrés et profanes de l'ancienne Egypte( ${ }^{(4)}$, e consiste na tradução de uma «inscrição esculpida sobre uma estela de granito, descoberta nas ruínas do templo funerário do faraó Merenptah (1224-1204 a. C. ${ }^{(5)}$ actualmente no Museu Egípcio do Cairo(6), e dá conta, sucessivamente, da construção de um "templo funerário na margem oeste do rio, em Tebas» "(7), "O templo de Lucsor»(8), "um jardim, ao pé de Lucsor»(9), "a barca sagrada de Amon» "(10), a "erecção de um pilone em Karnak»(11), e "um outro monumento... em Soleb, no Sudão»(12).

O que nesse texto mais se evidencia é a intenção, ou o sonho, de todas essas construções alcançarem uma perenidade, que roçaria a "eternidade e a infinita duração". Encontra-se assim expressa, e de uma maneira quase redundante, apologética e utópica, remetendo 
para a dimensão mitológica ${ }^{(13)}$, a intenção ou desejo, que poderá estar na origem do conceito romano da firmitas, como uma das finalidades da arquitectura, especialmente das dos edifícios públicos ${ }^{(14)}$.

A par da exegese da perenidade, que no texto relativo ao monumento erigido em Soleb, um pouco acima da terceira catarata, actual Sudão, se expressa como referida à construção de um "templo de [para durar] milhões de anos» ${ }^{(15)}$, encontra-se um contínuo apelo à magnificência, à sumptuosidade e à ornamentação exuberante, tudo concorrendo para uma "beleza... ainda mais magnífica", como é afirmado numa passagem. - De resto, veja-se:

"O templo todo inteiro era trabalhado em ouro, o seu chão estava ornamentado de prata, todas as suas portas eram em electrum [mistura de ouro e prata]; era largo, extremamente grande, construído para durar eternamente, e ornamentado com esta muito importante estela; eram numerosas as estátuas do rei, de granito de Elefantina, de grés, de todo a espécie de pedras preciosas excelentemente trabalhadas, como obras (que deviam durar) para a eternidade. Elas elevavam-se, resplandecentes, até ao céu e os seus raios, nos rostos, eram semelhantes aos do disco solar quando refulge ao despontar a aurora»(16).

O tão propalado carácter utilitário e funcional da arte e arquitectura egípcia, desvinculado de qualquer intenção estética, cujas realizações, mesmo as mais notáveis, visariam, antes de mais, fazer funcionar magicamente, como que num ritual, certos aspectos do que se considerava realidade, fosse a ressurreição no Além, fosse o cumprimento da maet, ou as obrigações perante o ka (o eu social), ou ainda outras diversas práticas religiosas e sociais, não dispensaria o sentido da beleza, talvez até incentivasse a dimensão do fenómeno estético, que preenche toda a arte e arquitectura egípcia, quase chegando a dar-se a ilusão de ser o culto da beleza, ou a "volição estética»(17), a sua finalidade essencial. - E de facto, é, a par do desejo ou sonho de perenidade das construções, a dimensão estética, o constante apelo à beleza o que mais se evidencia neste texto, onde se descreve a actividade edificatória de Amen-hotep III $^{(18)}$, "grande construtor de palácios divinos". - Para mais, veja-se:

Continuando a descrição do templo funerário:

"O templo estava fornecido também de uma "estela do rei", trabaIhada em ouro e em múltiplas pedras preciosas. Mastros com bandeirolas, feitos de electrum, estavam fixados diante da fachada; era semelhante ao horizonte do céu, quando Ré nele se levanta.»(19) 
Alusivo à construção do templo de Lucsor:

"O rei do Alto e Baixo Egipto, senhor do Duplo País, Nebmaetré, herdeiro de Ré, o filho de Ré, senhor das aspirações em glória, Amen-hotep, governante de Tebas, compraz-se em fazer uma construção para seu pai Amon-Ré, senhor dos tronos do Duplo País, em Lucsor, de bela pedra branca de grés; amplo, extremamente grande, a sua beleza era ainda mais magnífica. Os seus muros eram de electrum, o seu chão de prata, todas as suas portas eram trabalhadas em (?), os seus pilones atingem o céu e confundem-se com as estrelas divinas. Quando o povo vê isto, louva e aclama sua majestade (dizendo): É o rei Nebmaetré que regozijou o coração de seu pai Amon, senhor do trono do Duplo País, o qual the consignou (em troca) todos os países estrangeiros - o filho de Ré, Amen-hotep, governante de Tebas, esfuziante reflexo de Ré, que pertence àquele que o pôs no mundo." ${ }^{(20)}$

A beleza do templo aparece como derivada dos materiais: "bela pedra branca de grés", "muros de electrum» (uma mistura de ouro e prata, materiais incorruptíveis), "chão de prata", as portas também, num material não especificado (talvez ouro(21)); depois, as dimensões do templo: "amplo, extremamente grande, a sua beleza era ainda mais magnífica", assim o reconhecimento das dimensões monumentais como intensificação da beleza; por fim, e a par da monumentalidade, a integração ou fusão com o cosmos (ou a paisagem, se se quiser repare-se que no texto anterior o fenómeno assinalado é designado como "horizonte do céu"), quando se evocam "os pilones [que] atingem o céu e se confundem com as estrelas divinas".

O contributo da qualidade dos materiais para a excelência ou o bom resultado final da obra, das dimensões e da monumentalidade para a sua magnificência, e da integração paisagística (neste caso vista como uma poética fusão com o cosmos, quer no aspecto físico quer no simbólico, ao tempo algo inextricáveis), sempre se fizeram reconhecer na teoria da arquitectura, a partir de Vitrúvio(22), como princípios determinantes da beleza ou "venustidade" das edificações, e pode-se considerar que se encontram aqui, significativamente, prefigurados.

Depois, o carácter lúdico, festivo, da recepção popular destas construções, e as intenções de regozijar a divindade, e conquistar o seu apoio para projectos de poder, que visariam, que esta, ao edificador, "lhe consignasse (em troca) todos os países estrangeiros". - Mas não se trataria de uma mera «relação de troca». O templo era destinado a Amon-Ré, a divindade suprema do antigo Egipto durante o Império Novo, logo tinha que ser edificado à sua dimensão e feição, 
ou à sua "escala", isto é, tomando como referência e termo de comparação a excelência, magnificência e beleza do próprio deus, e, também, as homólogas do rei, seu filho, destinado após a morte, ele próprio, a tornar-se um deus imortal. E é, acima de tudo, este anelo de imortalidade ou eternidade, que se evola dos monumentos egípcios e dos textos onde tudo isso está aludido.

De resto, o texto, que refere ainda a criação de «um jardim, ao pé de Lucsor» (23), descrito como «um pavilhão de prazer... um lugar de bem-estar... cultivado de todas as flores", e a construção de uma "barca sagrada de Amon»(24), em "madeira de cedro novo... ornamentada de prata... toda trabalhada em ouro; a grande capela era de electrum", destinada a "navegar para o Ocidente, durante milhões e milhões de anos", termina com um "discurso de Amon» ${ }^{25)}$ agradecendo todos os monumentos que tinham sido erigidos, porque "satisfaziam o coração dos deuses", e assim prometendo todo o seu apoio ao rei, seu "filho":

"Ó meu filho, que pertences ao meu corpo, meu bem amado Nebmaetré, minha imagem viva, que o meu corpo criou e que meteu ao mundo por mim Mut, senhora de Acheru em Tebas, dama dos Nove Arcos; ela elevou-te para seres o senhor único do povo. O meu coração regozija-se grandemente quando vejo a tua beleza, e então faço para a tua majestade coisas maravilhosas. A tua juventude será eternamente renovada, porque eu te instalei como o sol das Duas Margens.

Quando volto a minha cara para o Sul, faço maravilhas para ti. Faço que os chefes do vil país de Kuch venham ter contigo carregando sobre o dorso os seus tributos.

Quando volto a minha cara para o Norte, faço maravilhas para ti. Faço que venham ter contigo os países mais longínquos da Ásia, carregando sobre o dorso os seus tributos; eles oferecem-te os seus filhos, afim de que Ihes seja dado (em troca) o sopro da vida.

Quando volto a minha cara para o Ocidente, faço maravilhas para ti. Faço que tu te apoderes do país dos Tjehenu [parte da actual Líbia] de maneira que aí nada reste - construindo para cobertura esta fortaleza em nome da minha majestade, cingida de uma grande muralha que alcance o céu e equipada por meio de filhos dos chefes núbios.

Quando volto a minha cara para a luz, faço maravilhas para ti. Faço que venham ter contigo os países de Punt [actual Somália], trazendo todas as plantas agradáveis das suas terras, para te implorar a paz e respirar os sopros que tu distribuis.»(26)

O projecto de poder que subjaz à construção destes monumentos está aqui bem explicitado, e tem real correspondência no contexto 
histórico, pois trata-se da época do Império Novo, quando as fronteiras do Egipto atingiam parte da Mesopotâmia, da Líbia, e, para sul, se tinham estendido até ao actual Sudão, subjugando toda uma série de povos. Mas este expansionismo fora ditado por necessidades defensivas, vindo na sequência do período da dominação dos Hicsos, que tanto abalara o Egipto, e tanto contribuíra para a diluição do poder centralizado no faraó, que urgia agora restaurar. E o mito da origem divina deste, e sua consequente eternidade eram a melhor garantia de tal. Uma garantia que devia ser legitimada, alimentada e renovada através de obras grandiosas, monumentais, de uma perenidade pétrea e fulgurante beleza, que, melhor do que nada, simbolizariam a pretendida eternidade, cujo anelo remata o texto:

"O rei do Alto e Baixo Egipto, chefe dos Nove Arcos, senhor do Duplo País, Nebmaetré, o filho de Ré, seu bem amado Amen-hotep, governante de Tebas, cujos monumentos satisfazem o coração dos deuses; possa ele agir sendo dotado de vida, estabilidade, força, prosperidade, alegria, como Ré, eternamente.»(27)

Mas o desejo de eternidade, ou "sonho da perenidade", como se designou na epígrafe, não ficou exclusivo dos antigos Egípcios. Ele aparecerá mais tarde em Vitrúvio, quando, a propósito das muralhas da cidade, e depois de descrever os seus diversos materiais e processos de construção, conclui afirmando a possibilidade de "ter uma muralha sem defeito construída para a eternidade (ab aeternitatem perfectus habeatur sine uicios murus)» ${ }^{(28)}$.

BIBLIOGRAFIA (citada ou referida no texto)

AUFRÉRE, Sidney, GOLVIN, Jean-Claude, GOYON, Jean-Claude, L'Égypte restituée. Tome I: Sites et temples de Haute Égypte, Paris: Éd. Errance, 1994.

LALOUETTE, Claire, Textes sacrés et profannes de l'ancienne Egypte, I: Des Pharaons et des hommes, II: Mythes, contes et poésie, trad. et commentaires par..., préf. de P. Grimal, Paris: Éd. Gallimard, 2 vols., 1984.

ARAÚJo, Luís Manuel de (dir.), Dicionário do Antigo Egípcio, Lisboa: Editorial Caminho, 2001.

GRIMAL, Nicolas, Histoire de l'Égypte ancienne, Paris: Librairie Arthème Fayard, 1988.

VITRUVE, De l'architecture (De architectura), Livre I, texte établi, trad. et commenté par Ph. Fleury, Paris, 1990, Collection des Universités de France/Les Belles Lettres.

As restantes referências a Vitrúvio têm, para efeitos de indicação de livros, capítulos e parágrafos, também as edições de Paris, Collection Universités de France/Les Belles Lettres. 


\section{Notas}

(1) "Pour la gloire d'Amon. / Amenophis III, / Grand constructeur / De châteaux divins", in LALOUETTE, C., Textes sacrés et profannes de l'ancienne Egypte, I: Des Pharaons et des hommes, trad. et commentaires par..., préf. de P. GRIMAL, Paris, 1984, Éd. Gallimard, p. 62-63. - Julga-se ser esta a única edição do texto que se vai comentar, pelo que não foi possível confrontar esta versão com outras.

(2) Estas datas, que são as indicadas por LALOUETTE (ob. cit., n. 110, p. 294), devem ser consideradas como aproximadas, encontrando-se noutros autores e obras datas diferentes, embora não muito divergentes.

(3) Ver ARAÚJO, entrada "Amen-hotep: Amen-hotep III", in Idem (dir.), Dicionário do Antigo Egípcio, Lisboa, 2001, Caminho, pp. 59-60: «Foi um dos maiores monarcas construtores da XVIII dinastia, e do Antigo Egipto, com grandes obras nos templos de Lucsor e Karnak, e um pouco por todo o país, erigidas ao longo dos quase quarenta anos de reinado [...] No reinado de Amen-hotep III, a arte egípcia atingiu uma qualidade e um refinamento que até então não tinham sido alcançados. Esses aspectos vêem-se na decoração de vários túmulos de funcionários do seu tempo e na estatuária real e privada da época. As construções são espectaculares, com o exemplo mais significativo no templo de Amon em Lucsor (considerado o "Harém do Sul" de Amon), o III pilone do templo de Karnak, obras em Heliópolis, Mênfis, Abido, Hermópolis, Athribis, Bubastis, e outros locais, sendo muitos os templos situados na Núbia que datam do reinado, para além de obras de beneficiação e embelezamento em monumentos de reis anteriores. O seu grande palácio de Malkata desapareceu bem como o seu templo funerário". - Este templo funerário, desaparecido, tudo indica ser o monumento referido no texto em primeiro lugar, que se situaria na «margem Ocidental, em Tebas", e fora concebido para "a eternidade e a infinita duração". Enfim, ironias da história e da acção corrosiva do tempo. Daí, o "sonho da perenidade".

(4) LALOUETTE, C., Textes sacrés et profannes de l'ancienne Egypte, I: Des Pharaons et des hommes, II: Mythes, contes et poésie, trad. et commentaires par..., préf. de P. GRIMAL, Paris, 1984, Éd. Gallimard, 2 vols. - O texto encontra-se no I. ${ }^{\circ}$ volume, pp. $62-$ -67 , n. 110-51, p. 294-96.

(5) Ver ARAÚJO, entrada "Merenpath", in Idem (dir.), ob. cit. (2001), p. 562. - Este faraó terá destruído o templo funerário de Amen-hotep III, entre outros motivos, para aproveitar os materiais para a construção do seu próprio túmulo.

(6) LALOUETTE, ob. cit. (1984), n. 110, p. 294.

(7) LALOUETTE, ob. cit. (1984), pp. 62-63.

(8) LALOUETTE, ob. cit. (1984), pp. 63-64.

(9) LALOUETTE, ob. cit. (1984), p. 64.

(10) LALOUETTE, ob. cit. (1984), p. 65.

(11) LALOUETTE, ob. cit. (1984), pp. 65-66.

(12) LALOUETTE, ob. cit. (1984), p. 66.

(13) O mito da "eternidade ou infinita duração" faz parte da cosmologia dos antigos Egípcios, os quais, tomando como referência o percurso do Sol e a alternância dia-noite, imaginavam tudo como sendo objecto de contínua e cíclica renovação, em especial, os deuses e os faraós, concebidos como filhos de deuses, ou mesmo, deuses, eles próprios. Por outro lado, é de lembrar que o tópico da infinita duração veio a ser uma constante da literatura utópica, onde se faz sentir o desejo de parar o tempo e instituir um estado definitivo, destinado a durar "milénios" (o milenarismo é de natureza utópica), ou para sempre... 
(14) VITRUVE, De l'architecture (De architectura), Livre I, III, 1-2, texte établi, trad. et commenté par PH. Fleury, Paris, 1990, Collection des Universités de France/Les Belles Lettres, pp. 19-20. - É no seguimento da menção tipificadora das obras comuns e dos edifícos públicos que a tríade vitruviana é explicitada, parecendo referir-se essencialmente a este tipo de edificações.

(15) LALOUETTE, ob. cit. (1984), p. 66 . - O templo construído para durar "milhões de anos" é descrito desta maneira: "Construi para ti o teu templo de milhöes de anos, próximo de (aquele de) Amon-Ré, senhor dos tronos do Duplo País [...] aquele que aparece em glória graças a Maet [...] de bela pedra branca de grês, está feito para durar; trabalhado inteiramente em ouro, o seu pavimento está ornamentado de prata, todas as portas são de ouro; dois grandes obeliscos estão erigidos, um de cada lado."

(16) LALOUETTE, ob. cit. (1984), p. 63.

(17) Refere-se o conceito de Alois Riegl, de "Kunstwollen", por vezes traduzido como "intencionalidade estética", "vontade de arte", ou "volicão estetica". Uma expressão bem mais significativa... remetendo para o domínio dos desejos ou apetites, logo, dos sentidos.

(18) O longo reinado de Amen-hotep III é considerado por Nicolas Grimal como o de «l'apogée de la dynastie", e para esse apogeu bastante contaram as construções realizadas sob a égide deste faraó. - Ver GRIMAL, N., Histoire de l'Égypte ancienne, Paris, 1988, Fayard, pp. 285-90.

(19) LALOUETTE, ob. cit. (1984), p. 63.

(20) LALOUETTE, ob. cit. (1984), pp. 63-64.

(21) LALOUETTE, ob. cit. (1984), p. 66. - É de lembrar que eram de ouro as portas do "templo de milhões de anos".

(22) Vitrúvio alude amiudamente à necessária boa qualidade dos materiais e dos processos de construção: Livro I, II, 8; III, 2; V, 8; ainda, Livro II, III-X, Livro III, IV, 1-2; e Livro VI e VII, no essencial. - Refere os monumentos ou edifícios públicos (moenium et communium operum in publicis locis) a partir do Livro I, III, 1, e embora referindo-se mais às proporções do que às dimensões, estas, e a sua monumentalidade, não deixam de estar subentendidas. Quanto à integração paisagística, faz parte daquilo a que designa por naturalis decor, de que trata a partir do Livro I, II, 5, onde o conceito é definido. Também na questão da procura de locis saluberrimus (Livro I, IV, 1ss.), para a localização e implantação das cidades se faz sentir a questão da integração na paisagem, ou no ambiente. - O enfoque e a tónica de Vitrúvio, porém, são de um tipo já muito diferente, revelando uma perspectiva laica e pragmática da arquitectura, o que mostra que também na teoria da arquitectura se processara a pretendida passagem do mito para o logos, ou se faz observar a dessacralização da arquitectura a que já anteriormente se aludiu, a propósito da arquitectura mesopotâmica.

(23) LALOUETTE, ob. cit. (1984), p. 64.

(24) LALOUETTE, ob. cit. (1984), p. 65.

(25) LALOUETTE, ob. cit. (1984), pp. 66-67.

(26) LALOUETTE, ob. cit. (1984), pp. 66-67.

(27) LALOUETTE, ob. cit. (1984), p. 67.

28) VITRUVE, ob. cit. (1990), V, 8, p. 31. 